\title{
Screening of Suitable Plant Regeneration Protocols for Several Capsicum spp. through Direct Organogenesis
}

\author{
Marina Martínez-López ${ }^{1}$, Ana García-Pérez ${ }^{2}$, Esther Gimeno-Páez ${ }^{1}$, Jaime Prohens ${ }^{1, *(D)}$, Santiago Vilanova ${ }^{1}$ \\ and Edgar García-Fortea ${ }^{2}$ (D) \\ 1 Instituto de Conservación y Mejora de la Agrodiversidad Valenciana, Universitat Politècnica de València, \\ Camí de Vera s/n, 46022 Valencia, Spain; mamar75m@etsiamn.upv.es (M.M.-L.); esgipa@upv.es (E.G.-P.); \\ sanvina@upvnet.upv.es (S.V.) \\ 2 Seeds for Innovation, Calle Regaliz, 6, 04007 Almería, Spain; ana.garcia@seeds4i.com (A.G.-P.); \\ edgar.garcia@seeds4i.com (E.G.-F.) \\ * Correspondence: jprohens@btc.upv.es
}

Citation: Martínez-López, M.; García-Pérez, A.; Gimeno-Páez, E.; Prohens, J.; Vilanova, S.; García-Fortea, E. Screening of Suitable Plant Regeneration Protocols for Several Capsicum spp. through Direct Organogenesis. Horticulturae 2021, 7, 261. https://doi.org/ 10.3390/horticulturae7090261

Academic Editors: Federica Blando, Claudia Ruta and Sergio

Ruffo Roberto

Received: 22 June 2021

Accepted: 20 August 2021

Published: 25 August 2021

Publisher's Note: MDPI stays neutral with regard to jurisdictional claims in published maps and institutional affiliations.

Copyright: (c) 2021 by the authors. Licensee MDPI, Basel, Switzerland. This article is an open access article distributed under the terms and conditions of the Creative Commons Attribution (CC BY) license (https:/ / creativecommons.org/licenses/by/ $4.0 /)$.

\begin{abstract}
Peppers (Capsicum spp.) are recalcitrant to in vitro culture regeneration, making the application of in vitro-based breeding strategies difficult. We evaluated the impact of different combinations of auxins, cytokinins and micronutrients on the induction of direct organogenesis in cotyledon and hypocotyl explants of C. annuum, C. baccatum and C. chinense. We found variation in the regeneration response among species and type of explant. In this way, the average numbers of shoots per cotyledon and hypocotyl explant were, respectively, 1.44 and 0.28 for C. annuum, 4.17 and 3.20 for $C$. baccatum and 0.08 and 0.00 for $C$. chinense. Out of the six media, the best overall results were obtained with the medium Pep1, which contained $5 \mathrm{mg} / \mathrm{L}$ BAP (6-benzylaminopurine), $0.5 \mathrm{mg} / \mathrm{L}$ IAA (indole-3-acetic acid) and $0.47 \mathrm{mg} / \mathrm{L} \mathrm{CuSO}_{4}$, followed by a subculture in the same medium supplemented with $10 \mathrm{mg} / \mathrm{L} \mathrm{AgNO}_{3}$ (medium Pep1.2). The best result for the Pep1 + Pep1.2 medium was obtained for $C$. baccatum using cotyledon explants, with 8.87 shoots per explant. The explants grown in medium Pep1 + Pep1.2 were the ones with greener tissue, while overall the hypocotyl explants were greener than the cotyledon explants. Our results indicate that there is wide variation among Capsicum species in terms of regeneration. Our results suggest that the synergistic effect of copper and silver resulted in a higher regeneration rate of Capsicum explants. Explants with shoots were transferred to different media for elongation, rooting and acclimatization. Although acclimatized plantlets were obtained for C. baccatum and C. chinense, an improvement in these latter stages would be desirable for a high throughput regeneration pipeline. This work contributes to the improvement of Capsicum regeneration protocols using specific combinations of medium, explant and genotype, reaching the levels of efficiency required for genetic transformation and of gene editing technologies for other crops.
\end{abstract}

Keywords: direct organogenesis; $\mathrm{AgNO}_{3} ; \mathrm{CuSO}_{4} ;$ Capsicum annuum; Capsicum baccatum; Capsicum chinense

\section{Introduction}

Efficient direct organogenesis induction would have a large impact on the breeding of and research on peppers (Capsicum spp.). Worldwide, five Capsicum pepper species (C. annuum L., C. baccatum L., C. chinense Jacq., C. frutescens L. and C. pubescens L.) are cultivated over an area of 3.72 million hectares [1]. World pepper production reached 42.3 million tons in 2019, ranking sixth among all vegetables in terms of global production [1]. Despite the great advances achieved in the breeding and genomics of peppers [2,3], most Capsicum materials are considered as recalcitrant to in vitro culture techniques, making the application of conventional and modern breeding techniques that require in vitro regeneration more difficult [3,4]. Since Gunay and Rao [5] published the first work on the regeneration of pepper plants in 1978, numerous subsequent experiments have 
demonstrated the difficulties of pepper regeneration in in vitro culture, including natural morphogenetic recalcitrance, rosette bud formation, sensitivity to ethylene, and differences among genotypes [3,6]. Despite this, there are several studies of regeneration from different explants showing some success [6-11], although they do not reach the required efficiency for genetic engineering applications.

Capsicum explants are very sensitive to ethylene during their in vitro development, a characteristic that has been related to recalcitrance [10]. In this way, during in vitro culture, pepper explants usually develop chlorosis, abscission of the foliar primordia and loss of vigor [3]. One way to mitigate this effect is using inhibitors of the action of ethylene, which also improve morphogenesis by reducing recalcitrance, achieved by promoting cell elongation and division [3]. Among the ethylene inhibiting substances added to the culture medium, $\mathrm{AgNO}_{3}$ has been the most used for Capsicum [10-12].

To overcome the rosette bud formation (resistance to elongation), silver nitrate $\left(\mathrm{AgNO}_{3}\right)$ or phenylacetic acid (PAA) has been added to the culture media [10], although the problem still persists in many materials [3]. Other authors have successfully used copper $(\mathrm{Cu})$ to promote the elongation of shoots [13]. Additionally, differences in the organogenic response have been reported among different Capsicum species and genotypes. In this way, large differences in regeneration have been reported in several Capsicum species, including C. annuum, C. baccatum and C. chinense $[7,9,14]$. The differences found suggest that the variation associated with genotype in Capsicum materials is a limiting factor in the development of widely applicable regeneration protocols in Capsicum. In fact, individualized protocols are required for different genotypes [6]; so, cultivar-specific media formulations have been designed [15].

Many efforts have been made to achieve the successful regeneration of Capsicum. Regeneration has mainly been achieved via organogenesis [7,15-17]. These works reveal that the key factors in designing an efficient protocol for plant regeneration in Capsicum genotypes are, fundamentally, the appropriate choice of explant and the formulation of a medium supplemented with specific growth regulators. In this respect, Golegaonkar and Kantharajah [18], when investigating the formation of shoots from leaf and cotyledon explants in five $C$. annuum cultivars, reported that according to the percentage of contribution to the variation observed, the explant factor accounted for most of the total variation found $(49.7 \%)$, followed by the media (29.2\%) and the cultivar $(14.3 \%)$. Despite some occasional successes in Capsicum regeneration, the evaluation of differences among Capsicum species has not been widely studied. In particular, few works have studied regeneration in C. chinense and C. baccatum, two cultivated species that are cross-compatible with the economically most important C. annuum [19].

In this work, we evaluate the direct organogenesis regeneration in two explants (cotyledon and hypocotyl), several combinations of growth regulators and micronutrients, and three genotypes of the following species: C. annuum, C. baccatum and C. chinense. We aim at developing an efficient regeneration protocol and at understanding the mechanisms involved in the regeneration of pepper plants in in vitro culture. Our study will contribute to establishing an efficient, widely applicable Capsicum regeneration protocol that might be used for genetic transformation and gene editing technologies.

\section{Materials and Methods}

\subsection{Plant Material}

Three accessions from different Capsicum species (C. annuum, C. baccatum and C. chinense) with different origins and characteristics were used. The C. annuum accession was a breeding line of California Wonder (CW breeding line). For the two other species, the accessions BOL-37R (C. baccatum; Origin: Sillane, Chuquisaca, Bolivia) and ECU-973 (C. chinense; Origin: El Chaco, Napo, Ecuador) were used. The seeds were provided by the Germplasm Bank of Universitat Politècnica de València (Valencia, Spain). 


\subsection{Growth Conditions of the Starting Material}

For in vitro germination, the seeds were sterilized by immersion in $70 \%$ ethanol for $30 \mathrm{~s}$ and then in $20 \%$ commercial bleach for $10 \mathrm{~min}$, and they were finally washed three times, for $3 \mathrm{~min}$ per wash, in sterilized distilled water. After sterilization, 50 seeds per accession, distributed in five Petri dishes were germinated in the E0 medium from GarcíaFortea et al. [20]. The Petri dishes were incubated at a temperature of $25^{\circ} \mathrm{C}$ in the darkness to obtain elongated hypocotyls. The incubation lasted for three weeks, until cotyledons and hypocotyls reached the appropriate size for obtaining the explants. For cotyledons, the proximal and distal parts were excised while the hypocotyls were cut into fragments of about $1 \mathrm{~cm}$ long. The day before explants were obtained, the plates were exposed to light in order to facilitate the handling of cotyledons.

\subsection{In Vitro Culture of Explants}

A total of 510 explants, distributed over 102 Petri dishes were grown for the in vitro regeneration experiments. Six media, including a control medium, were used (Table 1). The formulation of growth regulators was based on the literature $[10,13,20,21]$. The media included two different concentrations of Murashige and Skoog (MS) medium [22] and sucrose, which were supplemented by combining different concentrations of the following growth regulators: 6-benzylaminopurine (BAP), indole-3-acetic acid (IAA), $\alpha$-naphthalene acetic acid (NAA), zeatin riboside (ZR), phenylacetic acid (PAA), copper sulphate $\left(\mathrm{CuSO}_{4}\right)$ and silver nitrate $\left(\mathrm{AgNO}_{3}\right)$ (Table 1$)$. The $\mathrm{pH}$ of all media was adjusted to 5.9.

Table 1. Composition of media used to induce direct organogenesis in Capsicum.

\begin{tabular}{|c|c|c|c|c|c|c|c|c|c|c|}
\hline Medium & $\begin{array}{c}\text { MS } \\
(\mathrm{g} / \mathrm{L})\end{array}$ & $\begin{array}{c}\text { Sucrose } \\
(\mathrm{g} / \mathrm{L})\end{array}$ & $\underset{(\mathrm{g} / \mathrm{L})}{\text { Gelrite }}$ & $\underset{(\mathrm{mg} / \mathrm{L})}{\text { BAP }}$ & $\underset{(\mathrm{mg} / \mathrm{L})}{\mathrm{IAA}}$ & $\underset{(\mathrm{mg} / \mathrm{L})}{\mathrm{NAA}}$ & $\underset{(\mathrm{mg} / \mathrm{L})}{\mathrm{ZR}}$ & $\underset{(\mathbf{m g} / \mathrm{L})}{\mathrm{PAA}}$ & $\begin{array}{c}\mathrm{CuSO}_{4} \\
(\mathrm{mg} / \mathrm{L})\end{array}$ & $\begin{array}{c}\mathrm{AgNO}_{3} \\
(\mathrm{mg} / \mathrm{L})\end{array}$ \\
\hline Control & 4.4 & 30 & 7 & - & - & - & - & - & - & - \\
\hline Pep1 a & 4.4 & 30 & 7 & 5 & 0.5 & - & - & - & 0.47 & - \\
\hline Pep2 & 4.4 & 30 & 7 & 10 & - & 0.1 & - & - & - & - \\
\hline Pep3 ${ }^{b}$ & 4.4 & 30 & 7 & 5 & 1 & - & - & - & - & - \\
\hline Pep4 & 4.4 & 30 & 7 & 5 & - & - & - & 3 & 0.47 & - \\
\hline Pep5 & 2.2 & 15 & 7 & - & - & - & 2 & - & - & - \\
\hline
\end{tabular}

a The explants in Pep1 medium were subcultured after three weeks to Pep1.2 medium, with the same composition as Pep1, supplemented with $10 \mathrm{mg} / \mathrm{L}$ of $\mathrm{AgNO}_{3} .{ }^{\mathrm{b}}$ The explants in Pep3 medium were subcultured after three weeks to Pep3.2 medium, with the same composition as Pep3, supplemented with $10 \mathrm{mg} / \mathrm{L}$ of $\mathrm{AgNO}_{3}$. Abbreviations: MS: Murashige and Skoog medium, BAP: 6-benzylaminopurine, IAA: indole-3-acetic acid, NAA: $\alpha$-naphthalene acetic acid, ZR: zeatin riboside, PAA: phenylacetic acid. The pH of all media was adjusted to 5.9.

Pep1 medium was made up of MS and sucrose and supplemented with BAP, IAA and $\mathrm{CuSO}_{4}$ (Table 1). The chosen BAP concentration $(5 \mathrm{mg} / \mathrm{L})$ was the most frequently reported in the bibliography for pepper $[10,13]$ and the IAA concentration was $0.5 \mathrm{mg} / \mathrm{L}$. The $\mathrm{CuSO}_{4}$ concentration $(0.47 \mathrm{mg} / \mathrm{L})$ was 30 times higher than the $\mathrm{MS}$ level of $\mathrm{CuSO}_{4}$ and was used to check if this element induced elongation of the shoots [13]. The subculture medium Pep1.2 was prepared with the same formulation as Pep1, with the addition of $\mathrm{AgNO}_{3}(10 \mathrm{mg} / \mathrm{L})$ to evaluate if it inhibited the action of ethylene and improved the organogenesis of shoots [10]. The Pep2 medium was prepared using the same concentrations of MS and sucrose as Pep1, and supplemented with BAP (10 mg/L) combined with $0.1 \mathrm{mg} / \mathrm{L}$ of NAA [21]. The Pep3 medium was similar to Pep1, but with twice the concentration of IAA and without $\mathrm{CuSO}_{4}$ (Table 1). After three weeks, the explants were subcultured in Pep3.2 medium, with the same composition as Pep3, but supplemented with $\mathrm{AgNO}_{3}$ [10]. Pep4 medium included $\mathrm{CuSO}_{4}(0.47 \mathrm{mg} / \mathrm{L})$, BAP (5 mg/L) and PAA (3 mg/L) [13]. Pep5 medium was formulated with half concentration of salts (MS) and sucrose compared to the other media and contained ZR (2 mg/L). This medium was the best for eggplant regeneration [20]. A base medium with the same concentrations of salts and sucrose as Pep1-Pep4, without any hormonal or additional mineral supplements, was used as a control (Table 1).

The explants were cultured with a photoperiod of $16 \mathrm{~h} \mathrm{light} / 8 \mathrm{~h}$ dark at a temperature of $25{ }^{\circ} \mathrm{C}$. Gro-Lux F36W/GRO fluorescent tubes (Sylvania, Erlangen, Germany) with irradiance values of 100-112 $\mu \mathrm{mol} \mathrm{m}^{-2} \mathrm{~s}^{-1}$ were used. After three weeks, the explants in Pep2, Pep4, Pep5 and the control media were transferred to fresh media to avoid the 
depletion of nutrients and growth regulators. The explants in Pep1 and Pep3 media were also subcultured, in this case to Pep1.2 and Pep3.2 media, respectively. In these new fresh media, the explants were kept for one month.

\subsection{Response of Explants and Their Characterization}

After one month of culture, the presence of callus in the explants was evaluated using the following scoring system: explant without callus (0), explant with callus at either the proximal or distal cut edge (1), explant with callus at both proximal and distal edges (2). Images of the different structures of explants were taken using a stereo microscope Leica $\mathrm{S}$ Apo (Leica, Wetzlar, Germany) and images of the plates were also taken.

One month later (i.e., two months after the start of the explant culture), the state of the tissue and the number of shoots per explant were recorded. In some explants, it was difficult to count all the shoots as shown in Figure 1. The nucleus of shoot formation $(0.5 \mathrm{~cm}$ in diameter) was defined to simplify the count, and this was the value we used to calculate the number of shoots. However, after a period of culture, we saw that individual shoots were obtained (Figure 1). The state of the tissue was evaluated by assigning the following values to each state: green tissue (1), dull greyish brown tissue (2), and dead tissue (3) (Figure 2). The percentage of cotyledon and hypocotyl explants with shoots after two months was also calculated.

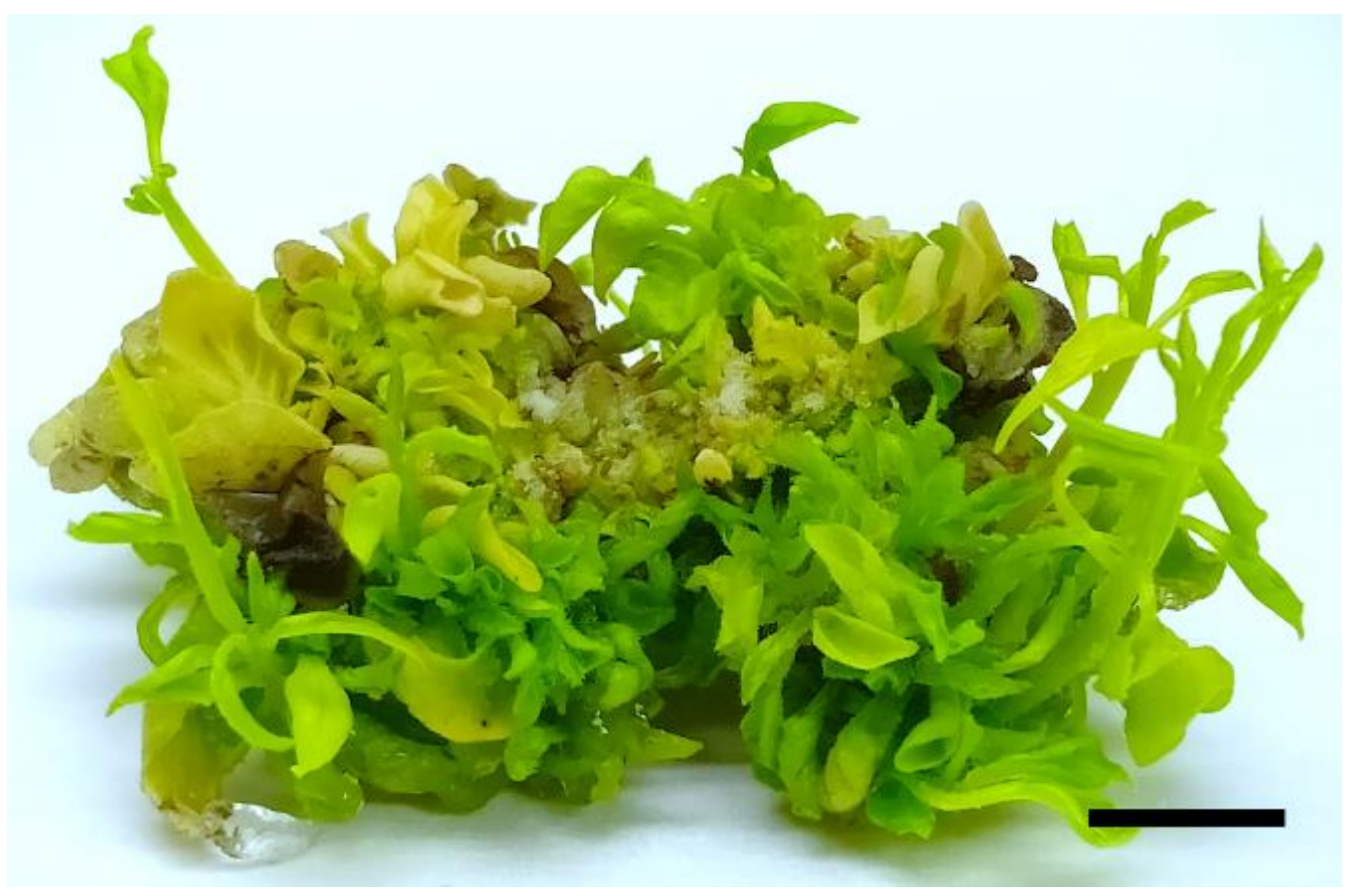

Figure 1. Differentiated Capsicum shoots obtained after two months of culture of cotyledons on Pep1 + Pep1.2 medium (Pep1: $5 \mathrm{mg} / \mathrm{L}$ BAP, $0.5 \mathrm{mg} / \mathrm{L} \mathrm{IAA}$ and $0.47 \mathrm{mg} / \mathrm{L} \mathrm{CuSO}_{4}$; Pep1.2: same composition as Pep1 plus $10 \mathrm{mg} / \mathrm{L} \mathrm{AgNO}_{3}$ ). The bar for reference measures $1 \mathrm{~cm}$. 


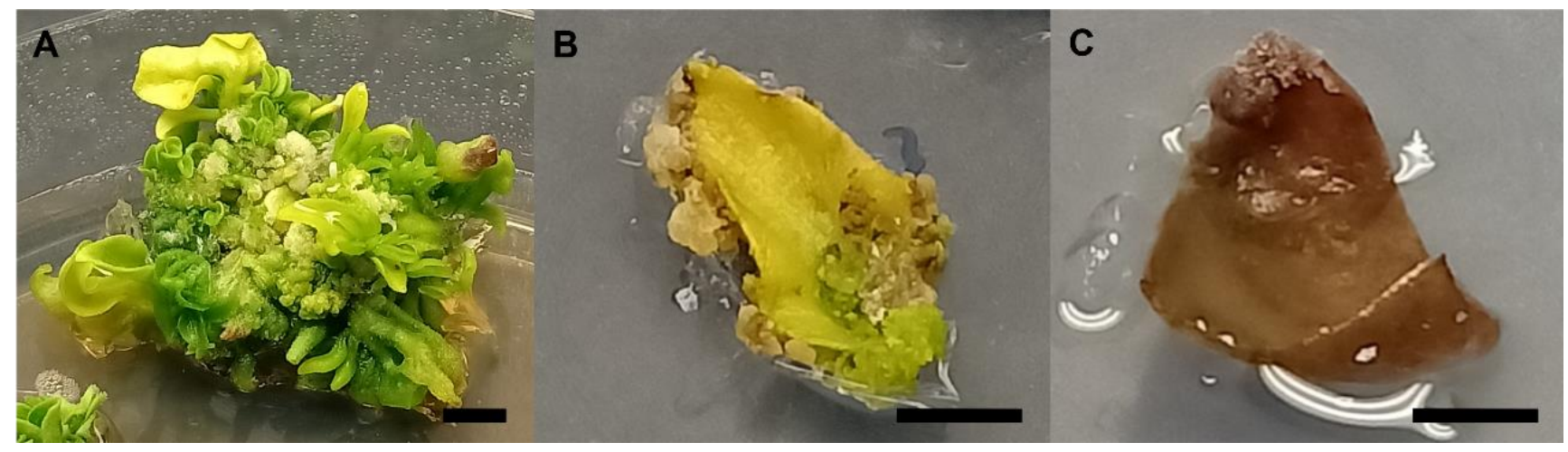

Figure 2. Scoring tissue status (scale from 1 to 3) for Capsicum explants. (A) green tissue (1); (B) dull greyish brown tissue (2); (C) dead tissue (3). In each of the subfigures, the bar for reference measures $0.5 \mathrm{~cm}$.

\subsection{Elongation, Rooting and Acclimatization}

Some of the explants with regenerated shoots from the Pep1 + Pep1.2 medium were placed in E0 medium (Table 2), which was free of growth regulators [20], to eliminate the residual effect of the growth regulators from the previous medium. After a week, the explants were subcultured for a week in ELG elongation medium (Table 2). After that, the explants with elongated shoots were transferred back to the E0 medium until the individualization of the shoots and their cultivation in rooting medium. The excised shoots were cultured in R1 or R2 medium [20] (Table 2). Once the shoots had enough roots and had grown to an appropriate size, they were passed to the acclimatization phase. The elongated and rooted shoots were planted in small pots with Neuhaus Humin-Substrat N3 growing substrate (Klasmann-Deilmann GmbH, Geeste, Germany) and covered with a plastic glass in which a water spray treatment was applied daily to maintain humidity. The pots were placed in a chamber under $16 \mathrm{~h} \mathrm{light} / 8 \mathrm{~h}$ dark photoperiod conditions at $25^{\circ} \mathrm{C}$. The plastic glass was gradually raised as the plants acclimatized and needed less moisture.

Table 2. Composition of the elongation and rooting means used in the preliminary tests.

\begin{tabular}{cccccccc}
\hline Medium & $\begin{array}{c}\text { MS } \\
(\mathbf{g} / \mathrm{L})\end{array}$ & $\begin{array}{c}\text { Sucrose } \\
(\mathbf{g} / \mathrm{L})\end{array}$ & $\begin{array}{c}\text { Gelrite } \\
(\mathbf{g} / \mathrm{L})\end{array}$ & $\begin{array}{c}\text { Citric Acid } \\
(\mathbf{m g} / \mathrm{L})\end{array}$ & $\begin{array}{c}\mathrm{GA}_{3} \\
(\mathbf{m g} / \mathbf{L})\end{array}$ & $\begin{array}{c}\text { IAA } \\
(\mathbf{m g} / \mathrm{L})\end{array}$ & $\begin{array}{c}\text { IBA } \\
(\mathbf{m g} / \mathrm{L})\end{array}$ \\
\hline E0 & 2.6 & 15 & 7 & - & - & - & - \\
ELG & 4.4 & 30 & 7 & 1 & 1 & 1 & - \\
R1 & 2.2 & 15 & 7 & - & - & - & 0.5 \\
R2 & 2.2 & 15 & 7 & - & - & - & 1 \\
\hline
\end{tabular}

Abbreviations: MS: Murashige and Skoog medium, $\mathrm{GA}_{3}$ : gibberellic acid, IAA: indole-3-acetic acid, IBA: indole-3-butyric acid. The $\mathrm{pH}$ of all media was adjusted to 5.9.

\subsection{Statistical Analysis}

Statistical analysis was performed with R software (version 3.6.1) [23]. For the regeneration parameters, the independence of variables was evaluated using a distribution-plot test, homoscedasticity with Bartlett's test, and normality with the Shapiro-Wilk test. Since none of these three criteria were met, the Kruskal-Wallis non-parametric test at $p<0.05$ was used, followed by the pairwise Wilcoxon test for separation of means. To complete the information, the mean, mode, median and range of each data set were obtained, as is usually the case with non-parametric data analyses.

For the elongation data, the number of explants transferred to the elongation medium, the number of explants with elongated shoots and the number of shoots per explant were counted for both cotyledon and hypocotyl. From the data obtained, the percentage of explants with elongated shoots was calculated with respect to the total number of explants exposed to the ELG medium (Table 2), together with the standard error, as well as the average elongated shoots per explant and the standard deviation. For rooting, the number of shoots transferred to R1 or R2 media and the number of rooted shoots were counted. 
From these data, the percentage of shoots with roots together with the standard error were calculated for each rooting medium.

\section{Results}

\subsection{Differences in Organogenic Response According to Explant and Medium}

For $C$. annuиm, no significant differences were observed among cotyledon and hypocotyl explants for the number of cut edges with calli, with the mode and the median set as 2 for both explants (Table 3). The state of the tissue after two months was better for hypocotyl, with a mean of 1.54, which is closer to 1 (greener, Figure 2) than the result for cotyledon (1.94), with a median of 1 . The most organogenic explant for the regeneration of shoots in C. annuum was cotyledon with a mean of 1.44 shoots per explant (two months), although the mode and median were 0 (Table 3 ).

Table 3. Organogenesis of $C$. annuum explants. Mean, statistical significance (groups defined with lower-case letters, $p<0.05$ ), mode, median and range of the number of cut edges with calli ( $n$; after one month); the tissue state (measured on a 1-3 scale-1 = green tissue, 2 = dull greyish brown tissue; 3 = dead tissue-after two months) and the number of shoots per explant (n; after two months) depending on the type of explant (cotyledon and hypocotyl) and the medium used for regeneration. An experimental session, with three replicates for each combination of factors and five explants per plate, was carried out.

\begin{tabular}{|c|c|c|c|c|c|c|c|c|c|c|c|c|}
\hline \multirow{2}{*}{ Factors } & \multicolumn{4}{|c|}{ Cut Edges with Calli } & \multicolumn{4}{|c|}{ Tissue State } & \multicolumn{4}{|c|}{ Number of Shoots Per Explant } \\
\hline & Mean $^{a}$ & Mode & Median & Range & Mean $^{a}$ & Mode & Median & Range & Mean $^{a}$ & Mode & Median & Range \\
\hline Explant & & & & & & & & & & & & \\
\hline Cotyledon & $1.50 \mathrm{a}$ & 2 & 2 & $0-2$ & $1.94 \mathrm{a}$ & 1 & 2 & $1-3$ & $1.44 \mathrm{a}$ & 0 & 0 & $0-9$ \\
\hline Hypocotyl & $1.56 \mathrm{a}$ & 2 & 2 & $0-2$ & $1.54 \mathrm{~b}$ & 1 & 1 & $1-3$ & $0.28 \mathrm{~b}$ & 0 & 0 & $0-8$ \\
\hline Medium & & & & & & & & & & & & \\
\hline Control & $0.50 \mathrm{c}$ & 0 & 0.5 & $0-1$ & $2.13 \mathrm{ab}$ & 3 & 3 & $1-3$ & $0.00 \mathrm{c}$ & 0 & 0 & $0-0$ \\
\hline Pep1 + Pep1.2 & $1.80 \mathrm{ab}$ & 2 & 2 & $1-2$ & $1.07 \mathrm{~d}$ & 1 & 1 & $1-2$ & $2.53 \mathrm{a}$ & 0 & 2 & $0-8$ \\
\hline Pep2 & $1.67 \mathrm{~b}$ & 2 & 2 & $1-2$ & $1.77 \mathrm{bc}$ & 2 & 2 & $1-3$ & $0.60 \mathrm{~b}$ & 0 & 0 & $0-8$ \\
\hline Pep3 + Pep3.2 & $1.73 \mathrm{~b}$ & 2 & 2 & $1-2$ & $1.47 \mathrm{C}$ & 1 & 1 & $1-2$ & $2.00 \mathrm{a}$ & 0 & 0 & $0-9$ \\
\hline Pep4 & $1.93 \mathrm{a}$ & 2 & 2 & $1-\overline{2}$ & $2.23 \mathrm{a}$ & 3 & 2.5 & $1-\overline{3}$ & $0.03 c$ & 0 & 0 & $0-1$ \\
\hline Pep5 & $1.53 \mathrm{~b}$ & 2 & 2 & $0-2$ & $1.80 \mathrm{abc}$ & 1 & 1 & $1-3$ & $0.00 \mathrm{c}$ & 0 & 0 & $0-0$ \\
\hline
\end{tabular}

${ }^{a}$ For each factor, means separated by different letters are significantly different at $p<0.05$ according to the non-parametric pairwise Wilcoxon test.

Comparing the media in C. annuum (Table 3), for the number of cut edges with calli, all the media, including the control, promoted calli formation, with the control being the medium that produced the least (0.50), followed by Pep5, Pep2 and Pep3 + Pep3.2 with means of 1.53, 1.67 and 1.73, respectively. Significant differences were observed between all the Pep media and the control, which induced negligible callus formation (Table 3). The medium with the greenest tissue was Pep1 + Pep1.2, with a mean of 1.07, which was the closest to the state of 1 (green, Figure 2). Finally, after two months, the media with the highest numbers of generated shoots were Pep1 + Pep1.2 and Pep3 + Pep3.2, with 2.53 and 2.00 shoots per explant, respectively, and significantly higher means than the other media. The median of Pep1 + Pep1.2 was 2, against the value of 0 held by the rest of the media. The Pep media with the worst shoot regeneration rates were Pep4 and Pep5, with values of 0.03 and 0.00 shoots per explant, respectively, which were not significantly different from the control (Table 3).

In C. baccatum, there were no differences between the two types of explant regarding the number of cut edges with callus (Table 4). The state of the tissue after two months was better in hypocotyl explants, with a mean of 1.32 , which was significantly closer to 1 (greener, Figure 2) than in cotyledon (1.81). No significant differences were observed between cotyledon and hypocotyl according to the number of shoots per explant (two months). Although the average for the formation of shoots (4.17 shoots/explant) in cotyledon was higher than in hypocotyl (3.20), the range was higher in cotyledon (up to 19) and both types of explant presented the same mode and median values (Table 4). 
Table 4. Organogenesis of C. baccatum explants. Mean, statistical significance (groups defined with lower-case letters, $p<0.05)$, mode, median and range of the number of cut edges with calli ( $n$; after one month), the tissue state (measured on a $1-3$ scale -1 = green tissue, 2 = dull greyish brown tissue; 3 = dead tissue-after two months) and the number of shoots per explant (n; after two months) depending on the type of explant (cotyledon and hypocotyl) and the medium used for regeneration. An experimental session, with three replicates for each combination of factors and five explants per plate, was carried out.

\begin{tabular}{|c|c|c|c|c|c|c|c|c|c|c|c|c|}
\hline \multirow{2}{*}{ Factors } & \multicolumn{4}{|c|}{ Cut Edges with Calli } & \multicolumn{4}{|c|}{ Tissue State } & \multicolumn{4}{|c|}{ Number of Shoots Per Explant } \\
\hline & Mean $^{a}$ & Mode & Median & Range & Mean $^{a}$ & Mode & Median & Range & Mean $^{a}$ & Mode & Median & Range \\
\hline \multicolumn{13}{|l|}{ Explant } \\
\hline Cotyledon & $0.98 \mathrm{a}$ & 1 & 1 & $0-2$ & $1.81 \mathrm{a}$ & 1 & 2 & $1-3$ & $4.17 \mathrm{a}$ & 0 & 3 & 0-19 \\
\hline Hypocotyl & $1.19 \mathrm{a}$ & 2 & 1 & $0-\overline{2}$ & $1.32 \mathrm{~b}$ & 1 & 1 & $1-3$ & $3.20 \mathrm{a}$ & 0 & 3 & $0-9$ \\
\hline \multicolumn{13}{|l|}{ Medium } \\
\hline Control & $0.33 c$ & 0 & 0 & $0-2$ & $2.13 \mathrm{a}$ & 3 & 2.5 & $1-3$ & $0.30 \mathrm{e}$ & 0 & 0 & $0-4$ \\
\hline Pep1 + Pep1.2 & $1.00 \mathrm{~b}$ & 0 & 1 & $0-\overline{2}$ & $1.10 \mathrm{~d}$ & 1 & 1 & $1-2$ & $7.87 \mathrm{a}$ & 6 & 8 & $0-19$ \\
\hline Pep2 & $0.80 \mathrm{~b}$ & 0 & 1 & $0-2$ & $1.47 \mathrm{bc}$ & 1 & 1 & $1-2$ & $1.57 \mathrm{~d}$ & 0 & 0.5 & $0-7$ \\
\hline Рep3 + Рep3.2 & $1.00 \mathrm{~b}$ & 1 & 1 & $0-2$ & $1.60 \mathrm{bc}$ & 1 & 1 & $1-3$ & $5.67 \mathrm{~b}$ & 8 & 5 & $0-18$ \\
\hline Pep4 & $1.70 \mathrm{a}$ & 2 & 2 & $0-\overline{2}$ & $1.43 \mathrm{c}$ & 1 & 1 & $1-3$ & $2.93 c$ & 0 & 2.5 & $0-7$ \\
\hline Pep5 & $1.67 \mathrm{a}$ & 2 & 2 & $0-\overline{2}$ & $1.67 \mathrm{~b}$ & 2 & 2 & $1-2$ & $3.77 \mathrm{bc}$ & 3 & 3 & $0-9$ \\
\hline
\end{tabular}

${ }^{a}$ For each factor, means separated by different letters are significantly different at $p<0.05$ according to the non-parametric pairwise Wilcoxon test.

Comparing the media for $C$. baccatum for the number of cut edges with callus after one month, all the Pep media had a higher callus production than the control (0.33) (Table 4). The Pep media with lower calli numbers were Pep2 (0.80), Pep1 + Pep1.2 (1.00) and Pep3 + Pep3.2 (1.00). Regarding the state of the tissue after two months of culture, Pep1 + Pep1.2 produced greener tissues than the other media, with an average of 1.10, closer to 1 (green state, Figure 2). After two months of culture, we observed that Pep1 + Pep1.2 was the medium that best induced direct organogenesis, with a mean of 7.87 shoots per explant, followed by Pep3 + Pep3.2 (5.67), Pep5 (3.77) and Pep4 (2.93). Pep2 had the lowest mean, with 1.57 shoots per explant (Table 4). In all media, the response was significantly higher than in the control. It is important to highlight the median and mode values of Pep1 + Pep1.2 (6 and 8 shoots per explant, respectively) and the wide range of variation (0-19). The mode and the median of Pep3 + Pep3.2 also stand out, with values of 8 and 5 , respectively (Table 4 ).

For $C$. chinense, the numbers of cut edges with calli were low compared to C. annuum or C. baccatum, with no significant differences among tissues (Table 5). However, significant differences were observed after two months of culture regarding the state of the tissue. At this date, the hypocotyl was the explant type with a greener state, with an average of 1.84, which is closer to 1 than the results for cotyledon, which averaged 2.12 (Figure 2). The number of shoots per explant was very low, with no significant differences among tissues (Table 5).

Comparing the media in $C$. chinense, the media with the lowest numbers of cut edges with callus were Pep3 + Pep3.2 and Pep4, which did not promote callus (even at lower rates than the control) (Table 5). The state of the tissue after two months was better in Pep1 + Pep1.2, with an average of 1.64, closer to the value of 1 (green tissue, Figure 2) than the others. Finally, no significant differences were observed between media for the number of shoots after two months, with no media resulting in the production of shoots, except for Pep3 + Pep3.2 and Pep4, in which a few, small shoots were obtained.

Therefore, considering the results obtained for explants, the cotyledon (Figure 3A,B) presented better average values for regeneration than the hypocotyl (Figure 3C,D) for the three species of Capsicum, although the hypocotyl explant remained greener (with means closer to 1) than the cotyledon. 
Table 5. Organogenesis of C. chinense explants. Mean, statistical significance (groups defined with lower-case letters, $p<0.05)$, mode, median and range of the number of cut edges with calli ( $n$; after one month), the tissue state (measured on a $1-3$ scale -1 = green tissue, 2 = dull greyish brown tissue; $3=$ dead tissue - after two months) and the number of shoots per explant (n; after two months) depending on the type of explant (cotyledon and hypocotyl) and the medium used for regeneration. An experimental session was carried out with three replicates for each combination of factors (except cotyledon, for which only two replicates were made due to the lack of plant material) and five explants per plate.

\begin{tabular}{|c|c|c|c|c|c|c|c|c|c|c|c|c|}
\hline \multirow{2}{*}{ Factors } & \multicolumn{4}{|c|}{ Cut Edges with Calli } & \multicolumn{4}{|c|}{ Tissue State } & \multicolumn{4}{|c|}{ Number of Shoots Per Explant } \\
\hline & Mean $^{a}$ & Mode & Median & Range & Mean ${ }^{a}$ & Mode & Median & Range & Mean $^{a}$ & Mode & Median & Range \\
\hline Explant & & & & & & & & & & & & \\
\hline Cotyledon & $0.19 \mathrm{a}$ & 0 & 0 & $0-2$ & $2.12 \mathrm{a}$ & 3 & 2 & $1-3$ & $0.08 \mathrm{a}$ & 0 & 0 & $0-4$ \\
\hline Hypocotyl & $0.31 \mathrm{a}$ & 0 & 0 & $0-2$ & $1.84 \mathrm{~b}$ & 1 & 2 & $1-3$ & $0.00 \mathrm{a}$ & 0 & 0 & $0-0$ \\
\hline Medium & & & & & & & & & & & & \\
\hline Control & $0.20 \mathrm{~b}$ & 0 & 0 & $0-1$ & $1.96 \mathrm{abc}$ & 1 & 1 & $1-3$ & $0.00 \mathrm{a}$ & 0 & 0 & $0-0$ \\
\hline Pep1 + Pep1.2 & $0.16 \mathrm{~b}$ & 0 & 0 & $0-1$ & $1.64 \mathrm{c}$ & 1 & 1 & $1-3$ & $0.00 \mathrm{a}$ & 0 & 0 & $0-0$ \\
\hline Pep2 & $0.08 \mathrm{bc}$ & 0 & 0 & $0-1$ & $2.08 \mathrm{~b}$ & 2 & 2 & $1-3$ & $0.00 \mathrm{a}$ & 0 & 0 & $0-0$ \\
\hline Pep3 + Pep3.2 & $0.00 \mathrm{c}$ & 0 & 0 & $0-0$ & $1.80 \mathrm{bc}$ & 1 & 2 & $1-3$ & $0.04 \mathrm{a}$ & 0 & 0 & $0-1$ \\
\hline Pep4 & $0.00 \mathrm{c}$ & 0 & 0 & $0-0$ & $1.80 \mathrm{bc}$ & 1 & 1 & $1-3$ & $0.16 \mathrm{a}$ & 0 & 0 & $0-4$ \\
\hline Pep5 & $1.12 \mathrm{a}$ & 1 & 1 & $0-2$ & $2.44 \mathrm{a}$ & 2 & 2 & $2-3$ & $0.00 \mathrm{a}$ & 0 & 0 & $0-0$ \\
\hline
\end{tabular}

${ }^{a}$ For each factor, means separated by different letters are significantly different at $p<0.05$ according to the non-parametric pairwise Wilcoxon test.
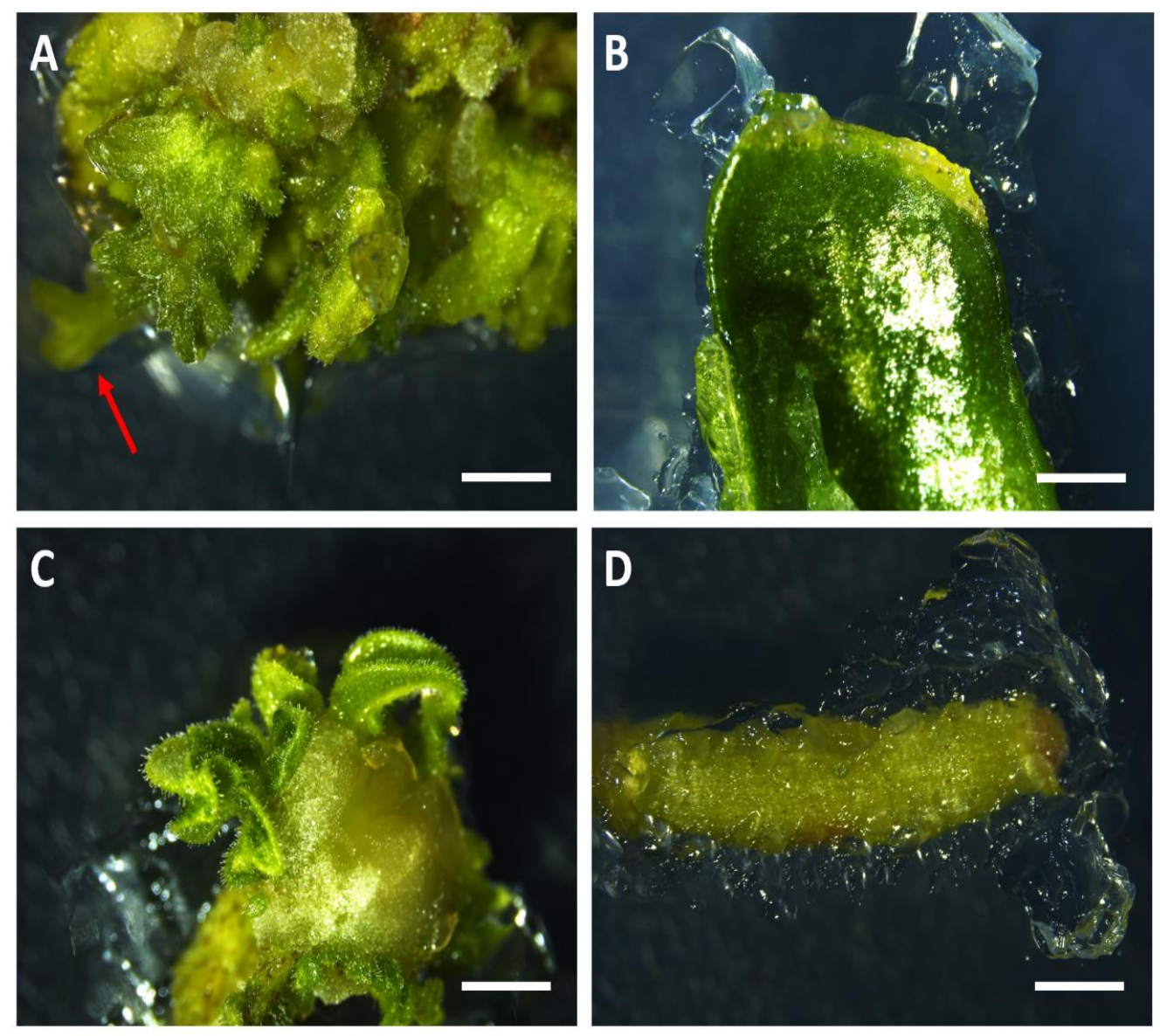

Figure 3. Comparison of shoot formation between Pep1 + Pep1.2 and control media in cotyledon and hypocotyl of C. baccatum after one month of culture. (A) Cotyledon with high organogenic response levels (the red arrow indicates the formation of a developed shoot). (B) Cotyledon with no organogenic response. (C) Hypocotyl with high organogenic response levels. (D) Hypocotyl with no organogenic response. The size of the bars is $5 \mathrm{~mm}$.

Regarding the state of the tissue, the Pep1 + Pep1.2 medium was the one with means closest to 1 (green) in the three species. For C. annuum and C. baccatum, after two months, 
Pep1 + Pep1.2 was the medium with the highest mean of shoots per explant in both species. In C. chinense, no medium had means significantly different to 0 .

\subsection{Differences in Shoot Formation among the Capsicum spp.}

Below, we present the results of organogenic response in cotyledon and hypocotyl explants of Capsicum spp. according to the in vitro culture medium. We found significant differences among media within the same explant, with the Pep1 + Pep1.2 combination the one with the best response in cotyledon and hypocotyl. On average, the cotyledon displayed a greater capacity for shoot regeneration than the hypocotyl. We also observed differences among species (Table 6). In this way, for cotyledon, we found significant differences between C. baccatum and C. chinense, while for hypocotyl, C. baccatum differed significantly from C. annuum and C. chinense (Table 6).

Table 6. Organogenic response in cotyledon and hypocotyl explants of Capsicum spp. Mean, mode, median and range of the number of shoots per explant $(n)$ after two months of culture for each type of explant, depending on the medium used for regeneration. An experimental session was carried out with three replicates for each combination of factors (except C. chinense cotyledon, for which only two replicates were made due to the lack of plant material) and five explants per plate.

\begin{tabular}{|c|c|c|c|c|c|c|c|c|}
\hline \multirow{2}{*}{ Medium } & \multicolumn{4}{|c|}{ Cotyledon } & \multicolumn{4}{|c|}{ Hypocotyl } \\
\hline & Mean $^{a}$ & Mode & Median & Range & Mean $^{a}$ & Mode & Median & Range \\
\hline C. annuum & $1.45 \mathrm{AB}$ & & & & $0.28 \mathrm{~A}$ & & & \\
\hline Control & $0.00 \mathrm{c}$ & 0 & 0 & $0-0$ & $0.00 \mathrm{~b}$ & 0 & 0 & $0-0$ \\
\hline Pep1 + Pep1.2 & $4.40 \mathrm{a}$ & 5 & 5 & $0-8$ & $0.67 \mathrm{a}$ & 0 & 0 & $0-4$ \\
\hline Pep2 & $1.20 \mathrm{~b}$ & 0 & 0 & $0-8$ & $0.00 \mathrm{~b}$ & 0 & 0 & $0-0$ \\
\hline Pep3 + Pep3.2 & $3.07 \mathrm{ab}$ & 0 & 2 & $0-9$ & $0.93 \mathrm{a}$ & 0 & 0 & $0-8$ \\
\hline Pep4 & $0.00 \mathrm{c}$ & 0 & 0 & $0-0$ & $0.07 \mathrm{ab}$ & 0 & 0 & $0-1$ \\
\hline Pep5 & $0.00 \mathrm{c}$ & 0 & 0 & $0-0$ & $0.00 \mathrm{~b}$ & 0 & 0 & $0-0$ \\
\hline C. baccatum & $4.17 \mathrm{~A}$ & & & & $3.20 \mathrm{~B}$ & & & \\
\hline Control & $0.00 \mathrm{c}$ & 0 & 0 & $0-0$ & $0.60 \mathrm{c}$ & 0 & 0 & $0-4$ \\
\hline Pep1 + Pep1.2 & $8.87 \mathrm{a}$ & 10 & 10 & 0-19 & $6.87 \mathrm{a}$ & 6 & 6 & $4-9$ \\
\hline Pep2 & $3.07 \mathrm{~b}$ & 1 & 3 & $0-7$ & $0.07 \mathrm{c}$ & 0 & 0 & $0-1$ \\
\hline Pep3 + Pep3.2 & $7.33 \mathrm{a}$ & 8 & 8 & 0-18 & $4.00 \mathrm{~b}$ & 5 & 4 & $0-8$ \\
\hline Pep4 & $2.60 \mathrm{~b}$ & 0 & 0 & $0-7$ & $3.27 \mathrm{~b}$ & 2 & 3 & $1-7$ \\
\hline Pep5 & $3.13 \mathrm{~b}$ & 3 & 3 & $0-9$ & $4.40 \mathrm{~b}$ & 6 & 6 & $0-7$ \\
\hline C. chinense & $0.08 \mathrm{~B}$ & & & & $0.00 \mathrm{~A}$ & & & \\
\hline Control & $0.00 \mathrm{a}$ & 0 & 0 & $0-0$ & $0.00 \mathrm{a}$ & 0 & 0 & $0-0$ \\
\hline Pep1 + Pep1.2 & $0.00 \mathrm{a}$ & 0 & 0 & $0-0$ & $0.00 \mathrm{a}$ & 0 & 0 & $0-0$ \\
\hline Pep2 & $0.00 \mathrm{a}$ & 0 & 0 & $0-0$ & $0.00 \mathrm{a}$ & 0 & 0 & $0-0$ \\
\hline Pep3 + Pep3.2 & $0.10 \mathrm{a}$ & 0 & 0 & $0-1$ & $0.00 \mathrm{a}$ & 0 & 0 & $0-0$ \\
\hline Pep4 & $0.40 \mathrm{a}$ & 0 & 0 & $0-4$ & $0.00 \mathrm{a}$ & 0 & 0 & $0-0$ \\
\hline Pep5 & $0.00 \mathrm{a}$ & 0 & 0 & $0-0$ & $0.00 \mathrm{a}$ & 0 & 0 & $0-0$ \\
\hline
\end{tabular}

${ }^{a}$ For each type of explant (cotyledon or hypocotyl), means within species separated by different lowercase letters and means between species separated by different uppercase letters are significantly different at $p<0.05$ according to the non-parametric pairwise Wilcoxon test.

The evaluation of the interaction effects between explant type and medium in the number of shoots regenerated revealed that in C. annuum (Table 6), the medium that provided the best response in cotyledon was Pep1 + Pep1.2, with a mean of 4.40 shoots per explant, followed by Pep3 + Pep3.2, with 3.07. Regarding the hypocotyl, Pep3 + Pep3.2 had the highest mean (0.93), followed by Pep1 + Pep1.2 (0.67). In addition, the medium with the highest percentage of explants with shoots after two months was Pep1 + Pep1.2 (Table 7), with $86.7 \%$ for cotyledon and $33.3 \%$ for hypocotyl. This was followed by Pep3 + Pep3.2, with $66.7 \%$ for cotyledon and $26.7 \%$ for hypocotyl. 
Table 7. Percentage of explants with shoots after two months in cotyledon and hypocotyl of the three Capsicum species (C. annuum, C. baccatum and C. chinense) in the six media used \pm standard error.

\begin{tabular}{ccccccc}
\hline \multirow{2}{*}{ Medium } & \multicolumn{2}{c}{ C. annuum } & \multicolumn{2}{c}{ C. baccatum } & \multicolumn{2}{c}{ C. chinense } \\
\cline { 2 - 7 } & Cotyledon & Hypocotyl & Cotyledon & Hypocotyl & Cotyledon & Hypocotyl \\
\hline Control & $0.0 \pm 0.0$ & $0.0 \pm 0.0$ & $0.0 \pm 0.0$ & $26.7 \pm 0.1$ & $0.0 \pm 0.0$ & $0.0 \pm 0.0$ \\
Pep1 + Pep1.2 & $86.7 \pm 0.1$ & $33.3 \pm 0.1$ & $86.7 \pm 0.1$ & $100.0 \pm 0.0$ & $0.0 \pm 0.0$ & $0.0 \pm 0.0$ \\
Pep2 & $46.7 \pm 0.1$ & $0.0 \pm 0.0$ & $93.3 \pm 0.1$ & $6.7 \pm 0.1$ & $0.0 \pm 0.0$ & $0.0 \pm 0.0$ \\
Pep3 + Pep3.2 & $66.7 \pm 0.1$ & $26.7 \pm 0.1$ & $86.7 \pm 0.1$ & $86.7 \pm 0.1$ & $10.0 \pm 0.1$ & $0.0 \pm 0.0$ \\
Pep4 & $0.0 \pm 0.0$ & $6.7 \pm 0.1$ & $46.7 \pm 0.1$ & $100.0 \pm 0.0$ & $10.0 \pm 0.1$ & $0.0 \pm 0.0$ \\
Pep5 & $0.0 \pm 0.0$ & $0.0 \pm 0.0$ & $80.0 \pm 0.1$ & $86.7 \pm 0.1$ & $0.0 \pm 0.0$ & $0.0 \pm 0.0$ \\
\hline
\end{tabular}

For C. baccatum, Pep1 + Pep1.2 and Pep3 + Pep3.2 were the media that most significantly improved the induction of organogenesis in cotyledon, with 8.87 and 7.33 shoots per explant, respectively (Table 6). Pep1 + Pep1.2 had a mode and a median of 10, and the upper range value reached 19 shoots. For Pep3 + Pep3.2, the mode and the median were 8 and the range reached up to 18 shoots per explant. In the hypocotyl, a better response was achieved with Pep1 + Pep1.2 (6.87), although the mean, mode, median and range values were lower than the best data obtained for cotyledon. Furthermore, Pep1 + Pep1.2 had a percentage of explants with shoots of $86.7 \%$ in cotyledon and $100.0 \%$ in hypocotyl, and Pep3 + Pep3.2 had $86.7 \%$ in both explants (Table 7).

In C. chinense, very low values were observed for shoot regeneration, with no significant differences in the number of shoots per explant in any of the explants evaluated (cotyledon and hypocotyl), although some shoots could be observed in cotyledon explants (Table 6). Regarding the percentage of explants with shoots after two months, Pep3 + Pep3.2 and Pep4 media were the only options able to regenerate shoots in cotyledon, both with a percentage of $10.0 \%$ (Table 7 ).

In general, for $C$. annuum and C. baccatum, the means were higher in cotyledon than in hypocotyl (Figure 4A,B). The means of Pep1 + Pep1.2 and Pep3 + Pep3.2 were the best for cotyledon and hypocotyl, except for the hypocotyl of $C$. annuum, which had a higher mean for Pep3 + Pep3.2. In C. chinense (Figure 4C), shoot regeneration was observed only for the hypocotyl in media Pep1 + Pep1.2 and Pep4, although with very low values.
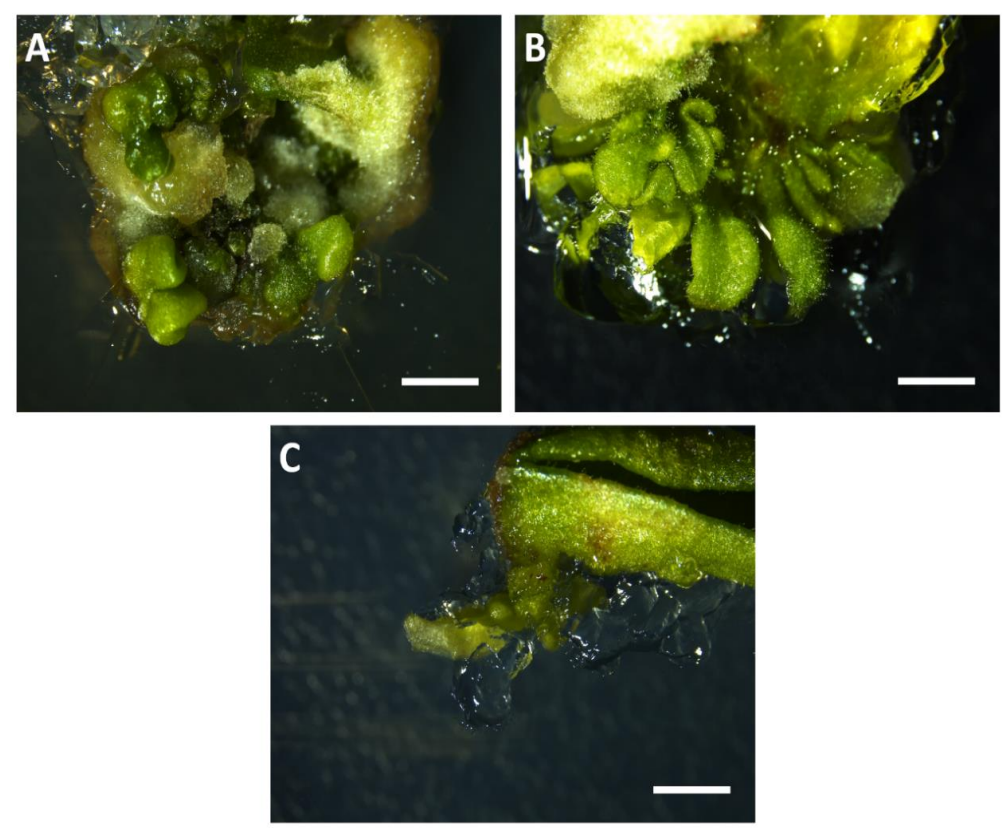

Figure 4. Comparison of shoot formation in cotyledon explants of the three Capsicum species evaluated. (A) C. annuum (intermediate response). (B) C. baccatum (high response). (C) C. chinense (low response). The size of the bars is $5 \mathrm{~mm}$. 


\subsection{Elongation, Rooting and Acclimatization}

A total of 20 cotyledon and 5 hypocotyl C. annuum explants from the Pep1.1 + Pep1.2 medium were transferred to ELG medium. In both tissues, $80.0 \%$ of the explants had elongated shoots, with an average of 2.13 elongated shoots per explant in cotyledon and 1.25 in hypocotyl (Table 8 ). For C. baccatum, 43 cotyledon and 51 hypocotyl explants were transferred to ELG medium. The cotyledon showed the best result with $46.5 \%$ of elongated shoots compared to $35.3 \%$ of hypocotyl (Table 8 ). The average number of elongated shoots per explant in C. baccatum was also higher in cotyledon (13.35) than in hypocotyl (3.94). In the case of $C$. chinense, five cotyledon explants were transferred to the elongation medium. No shoots from hypocotyl explants could be transferred since none with shoots were obtained. The percentage of elongated explants in C. chinense was $40.0 \%$ and the average number of elongated shoots per explant was 1.00.

Table 8. Elongation of shoots of C. annuum, C. baccatum and C. chinense in ELG medium (supplemented with IAA, GA 3 and citric acid). Data represent the number of cotyledon and hypocotyl explants transferred to elongation medium, percentage of explants with elongated shoots \pm standard error and average elongated shoots per explant \pm standard deviation.

\begin{tabular}{ccccccc}
\hline & \multicolumn{2}{c}{ C. annuum } & \multicolumn{2}{c}{ C. baccatum } & \multicolumn{2}{c}{ C. chinense } \\
\cline { 2 - 6 } & Cotyledon & Hypocotyl & Cotyledon & Hypocotyl & Cotyledon & Hypocotyl \\
\hline Number of explants to elongate & 20 & 5 & 43 & 51 & 5 & 0 \\
Explants with elongated shoot (\%) & $80.0 \pm 0.1$ & $80.0 \pm 0.2$ & $46.5 \pm 0.1$ & $35.3 \pm 0.1$ & $40.0 \pm 0.2$ & - \\
$\begin{array}{c}\text { Average number of elongated } \\
\text { shoots per explant }\end{array}$ & $2.13 \pm 0.26$ & $1.25 \pm 0.25$ & $13.35 \pm 1.69$ & $3.94 \pm 0.77$ & $1.00 \pm 0.00$ & - \\
\hline
\end{tabular}

In those cases where the shoots elongated, they presented a normal appearance within two weeks, reaching an approximate size of $2 \mathrm{~cm}$ and presenting a well-defined structure with a clearly differentiated apical meristem (Figure 5A). None of the C. annuum transferred explants (34 explants from cotyledon and 5 from hypocotyl) rooted in the R1 medium (with a lower concentration of IBA) (Table 9). No C. annuum explant was transferred to R2 medium. On the other hand, for C. baccatum (Table 9), 12.0\% of cotyledon explants (267 explants transferred to that medium) and $2.8 \%$ of hypocotyl (71 transferred explants) were rooted in the R1 medium. The use of the R2 medium (with the highest concentration of IBA) resulted in a greater formation of roots, with $54.5 \%$ of rooted cotyledon explants (22 transferred) and $17.9 \%$ of hypocotyl (28 transferred) (Figure 5B,C). In the case of C. chinense, one of the two shoot-excised cotyledon explants transferred to R1 medium (50\%) rooted (Table 9).

After the elongation and rooting processes, 42 seedlings were ready to start the acclimatization stage (Figure 5D). A total of 10 plants were acclimatized ( 7 from cotyledon and 2 from hypocotyl explants of C. baccatum and 1 from C. chinense cotyledon), representing $23.8 \%$ of the total initial plants obtained through the in vitro culture process (Figure 5E,F).

Table 9. Rooting of shoots of C. annuum, C. baccatum and C. chinense in R1 medium ( $0.5 \mathrm{mg} / \mathrm{L}$ of IBA) and in R2 medium $(1 \mathrm{mg} / \mathrm{L}$ of IBA). The data represent the number of cotyledon and hypocotyl explants transferred and percentage of rooted explants \pm standard error.

\begin{tabular}{|c|c|c|c|c|}
\hline & \multicolumn{2}{|c|}{ R1 } & \multicolumn{2}{|c|}{$\mathbf{R} 2$} \\
\hline & Cotyledon & Hypocotyl & Cotyledon & Hypocotyl \\
\hline \multicolumn{5}{|l|}{ C. annuum } \\
\hline Number of shoots to root & 34 & 5 & - & - \\
\hline Shoots with root $(\%)$ & $0.0 \pm 0.0$ & $0.0 \pm 0.0$ & - & - \\
\hline \multicolumn{5}{|l|}{ C. baccatum } \\
\hline Number of shoots to root & 267 & 71 & 22 & 28 \\
\hline Shoots with root $(\%)$ & $12.0 \pm 0.0$ & $2.8 \pm 0.0$ & $54.5 \pm 0.1$ & $17.9 \pm 0.1$ \\
\hline \multicolumn{5}{|l|}{ C. chinense } \\
\hline Number of shoots to root & 2 & - & 1 & - \\
\hline Shoots with root $(\%)$ & $50.0 \pm 0.4$ & - & $0.0 \pm 0.0$ & - \\
\hline
\end{tabular}



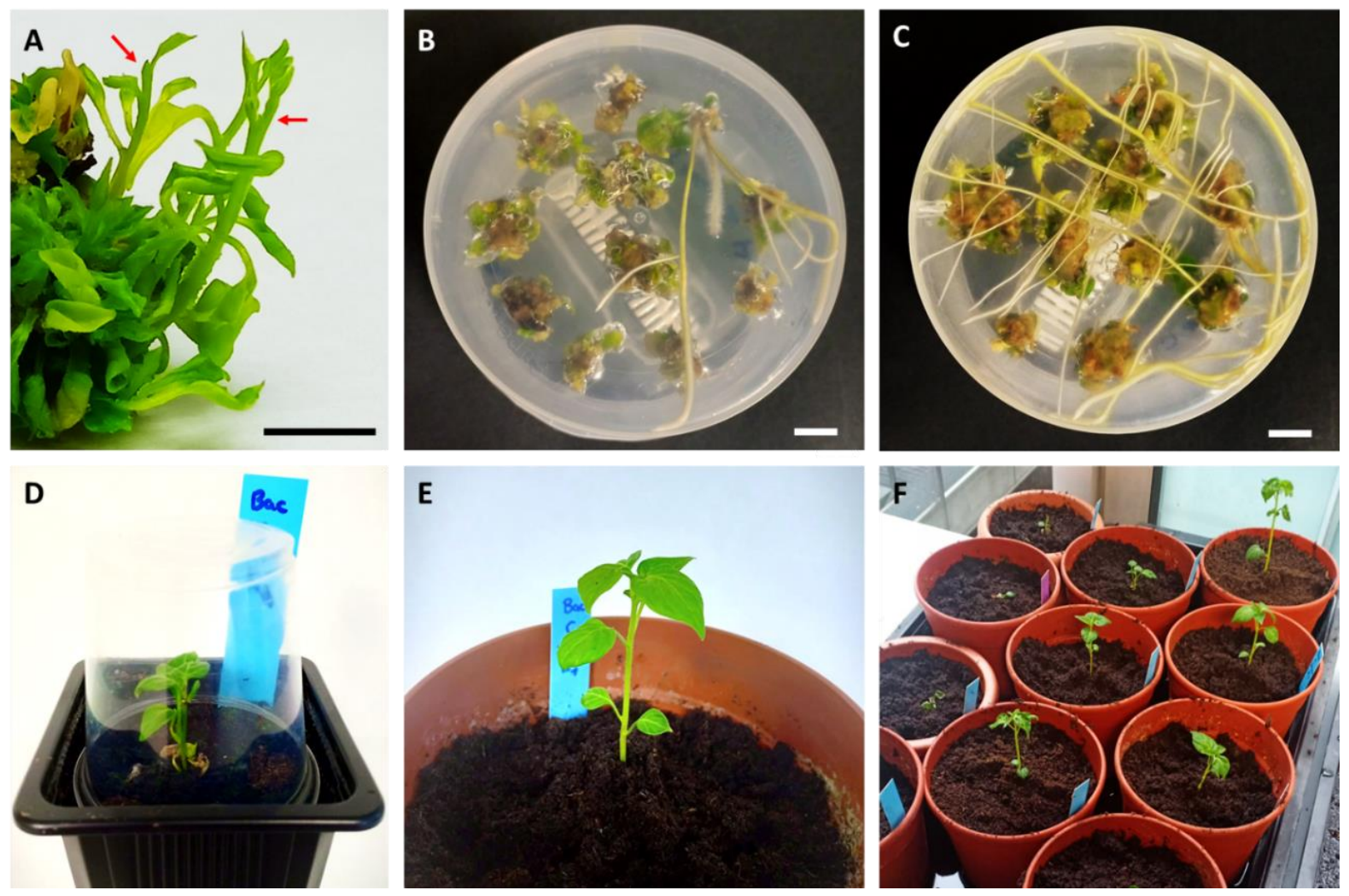

Figure 5. Elongation, rooting and acclimatization process of Capsicum spp. plants from the Pep1.1 + Pep1.2 organogenesis medium. Detail of the elongated shoots in a C. baccatum cotyledon explant, with clear apical meristems (arrows) at the top of the shoots (A). Images of isolated shoots of cotyledon explants of C. baccatum grown in R1 (B) and R2 (C) media. Acclimatization and rooting process of C. baccatum plants once they have been rooted in vitro, including the covering during the first stages with a plastic glass (D), which is gradually opened and removed (E) until the plantlets can develop without needing protection $(\mathbf{F})$. The bar for reference measures $1 \mathrm{~cm}$.

\section{Discussion}

Our results confirm the recalcitrant nature of Capsicum peppers for direct organogenesis regeneration, although variation was observed among species and accessions in the responses to in vitro culture $[7,9,14]$. We achieved good results for two of the three species tested, two of the most commercially important species: C. annuum and C. baccatum. The organogenesis we obtained was direct, which simplifies in vitro isolation and management of the shoots, and shortens the time needed to obtain a plant, as a callus differentiation phase is not necessary. Additionally, the risk of somaclonal variation is reduced.

Plant regeneration through organogenesis in Capsicum was reported from cotyledon, hypocotyl, leaf, shoot tip, embryo, root and seed explants $[6,10,11,18]$. We observed that, in general, the best explant for the regeneration of shoots via organogenesis in C. annuum and C. baccatum was cotyledon since it obtained the highest number of shoots per explant, although hypocotyl was the tissue with the healthiest state (green). This may seem like a contradiction, but there is not a direct relationship between the physiological state of a tissue and its organogenic capacity, although it is important that there is no oxidation or necrosis for the success of the protocol. As was the case in previous studies, Capsicum reported a higher regeneration in cotyledons compared to hypocotyls. In this respect, Gunay and Rao [5] observed a higher regeneration in cotyledons using a medium with IAA and BAP in a California Wonder (C. annuum) material. Other studies with a medium that had IAA and BAP [15,16,24], as well as Gammoudi et al. [10] using a medium similar to Pep3 + Pep3.2 medium tested here (containing IAA, BAP and $\mathrm{AgNO}_{3}$ ), reported that 
cotyledon was the most organogenic explant. In this respect, Sanatombi and Sharma [7] observed that at certain concentrations of IAA and BAP the hypocotyl was unable to regenerate. The superior organogenic competence of cotyledon has also been reported in other solanaceous crops, such as tomato [25] and eggplant [20], as well as in cucurbits such as melon [26].

Generally, the studies carried out in Capsicum have used media with a single combination of growth regulators, with the aim of evaluating the effects of different concentrations of growth regulators on the effectiveness of the treatment $[7,8,11,13,16]$. In our work, the media containing combinations of BAP and IAA provided better results. Comparing the results reported in this work with our Pep1 + Pep1.2 medium, Christopher and Rajam [27] observed better regeneration in C. annuum cultivars, but lower response in C. baccatum. Sanatombi and Sharma [7] achieved worse results in various cultivars of C. annuum using the same concentration of BAP and IAA tested in Pep3. The same occurred for Dabauza and Peña [15] regarding the percentage of explants with shoots, using the same concentrations as our Pep1 and Pep3 media. In general, the reported results indicate the importance of the synergistic effect of IAA in combination with BAP for improving shoot regeneration in Capsicum.

Other studies incorporate $\mathrm{AgNO}_{3}$ in the medium to improve the regeneration of several solanaceous species, such as tomato [28,29], potato [30,31], Solanum viarum [32] and Solanum nigrum [33]. In Capsicum, $\mathrm{AgNO}_{3}$ has been used with different combinations of auxins and cytokinins. In this way, Joshi and Kothari [13] obtained a high number of shoots per explant in C. annuum, using PAA and BAP with Ag. Similar results were obtained by Bora et al. [11] in C. chinense with a medium containing NAA and BAP. Valadez-Bustos et al. [14] achieved a high response for three cultivars of $C$. annuum and one of $C$. chinense with a medium containing IAA, BAP and $\mathrm{AgNO}_{3}$, similar to Pep3.2. With the same medium as Pep3 + Pep3.2, Gammoudi et al. [10] also observed a high percentage of explants with shoots in a range of cultivars. In the latter study, although the percentage was lower than in the medium without silver, the final result was that the medium with silver allowed for more shoots to be isolated, probably because the silver induced the regeneration of more shoots in each explant. The percentages of explants with shoots achieved in our work with Pep1 + Pep1.2 and Pep3 + Pep3.2 were higher than those reported by Gammoudi et al. [10], especially for C. baccatum.

The results obtained with Pep3 + Pep3.2, together with those described in the literature $[10,11,13,14]$ confirm that $\mathrm{AgNO}_{3}$ treatments increase the production of multiple shoots, improving the in vitro regeneration of a plant as recalcitrant as pepper. $\mathrm{AgNO}_{3}$ is likely to act as an inhibitor of ethylene activity and other compounds that cause chlorosis, primordial leaf abscission and loss of plant vigor [3,34]. In addition, silver also acts as a growth regulator and improves elongation, preventing the formation of shoot rosettes [10].

Joshi and Kothari [13] emphasized the role of a high level of copper in regeneration; they obtained an increase in the number of shoots per explant using a medium with 30 times more copper than the normal content of the MS medium, together with BAP and PAA, a medium similar to our Pep4. However, their best response was 17 shoots per explant, a much higher number than the one provided by Pep4, which only achieved a moderate regeneration in C. baccatum (around three shoots per explant) and did not work for $C$. annuum, probably due to the strong influence of the genotype $[3,9,10]$. The promoting effect of copper on the elongation and induction of shoots could be because it is an important component of the enzymes involved in electron transport and the biosynthesis of proteins and carbohydrates, which could play a role in the regeneration of plants [13,35]. On the other hand, copper favors the action of ethylene since it takes part in the creation of its receptors; therefore, it could negatively influence the success of organogenesis [13]. However, Ciardi and Klee [36] discussed the existence of an interactive effect between copper and silver, indicating that silver competes with copper for the ethylene receptorbinding site. This could lead to the synergistic action of both if they were added to the medium (as in Pep1 + Pep1.2) since silver could suppress the negative effect of ethylene 
by inhibiting its receptors, and at the same time, maintain copper levels and their positive effects on regeneration [13].

The results obtained here suggest that the cause of the Pep1 + Pep1.2 medium's higher organogenic response compared to the other media is not due to the plant growth regulators used, since the same growth regulators were tested with Pep3 + Pep3.2, resulting in a lower level of regeneration. Additionally, Pep1 + Pep1.2 worked better than the previously reported media containing only IAA and BAP $[10,15,16,24,37]$. Furthermore, Pep1 + Pep1.2 (with $\mathrm{AgNO}_{3}$ and $\mathrm{CuSO}_{4}$ ) induced greater regeneration than the two media from which it was formulated: Pep3 + Pep3.2 (with $\mathrm{AgNO}_{3}$ ) and Pep4 (with $\mathrm{CuSO}_{4}$ ). Therefore, we suggest that the key to the high regeneration achieved with Pep1 + Pep1.2 is the combined use of copper and silver, as a consequence of their positive interaction, which would enhance organogenesis. To the best of our knowledge, this effect has not been investigated or reported in Capsicum.

The response to the media was different for the three genotypes used. The best response was in $C$. baccatum, followed by $C$. annuum, with $C$. chinense being the most recalcitrant species. Previous studies generally aimed to evaluate the organogenic capacity of different cultivars, rather than the capacity of different species. Among the studies that used a similar media to Pep1 + Pep1.2 and Pep3 + Pep3.2, we highlight the work of Christopher and Rajam [27], who in contrast to our results, obtained a better response in five cultivars of $C$. annuum compared to one of $C$. baccatum, for both cotyledon and hypocotyl. Sanatombi and Sharma [8] reported a slight superiority of two cultivars of C. annuum compared to many others of $C$. chinense, with a very similar result to that obtained here for C. annuum. Valadez-Bustos et al. [14] reported a better response in the cultivar of $C$. chinense than in the three tested cultivars of $C$. annuum, with superior data to those found here. These results indicate great diversity in the organogenic response between cultivars and confirm the strong genotype-specificity in the regeneration capacity of Capsicum $[3,9,10]$, which limits the possibility of establishing common protocols, even within species.

The media used did not work for $C$. chinense. However, positive results were reported with other formulations, for example, a combination of kinetin, 2,4-D (2,4-dichlorophenoxyacetic acid) and $\mathrm{AgNO}_{3}$ induced up to 8.1 shoots per explant [17]. Media similar to those tested here could regenerate shoots; thus, Bora et al. [11] achieved up to 4.2 shoots per explant with a medium similar to Pep2 (NAA and BAP), using stem tips and seeds as explants. Sanatombi and Sharma [7] used IAA and BAP with satisfactory results (up to 8.9 shoots per cotyledon explant), while Hailu et al. [16] and Valadez-Bustos et al. [14], using a medium supplemented with IAA, BAP and $\mathrm{AgNO}_{3}$, similar to Pep3 + Pep3.2, obtained an average of 14.6 shoots per explant. These reports suggest that the absence of an organogenic response of $C$. chinense in our work is not due to the lack of effectiveness of the media per se, but to the great genotypic dependence on response capacity that is characteristic of the genus $[3,9,10]$.

The formation of rosette buds, which are resistant to elongation, is usually a limiting factor in the regeneration of Capsicum. Explants with numerous shoots that are not large enough for subculturing in a rooting medium usually result in a low percentage of acclimatized plants. Therefore, the incorporation of a previous elongation step may improve the rooting and acclimatization process $[16,20]$. The elongation medium used in our case seems to have a positive effect on the three Capsicum species, with elongation percentages greater than $40 \%$. In general, we observed no differences between the cotyledon and the hypocotyl in terms of elongation, with the differences residing in the number of elongated shoots, which were always higher in the cotyledon since it has more shoots per explant. On the other hand, the rooting media evaluated gave very different results. In the case of C. annuum, the results were negative since none of the shoots grown in the R1 medium rooted. On the other hand, C. baccatum had a better response, which was higher in the R2 medium (1 mg/L IBA). 
The survival rate in the acclimatization stage was lower than expected (less than $25 \%$ ), in contrast to that reported in the literature, at generally higher than $80 \%[7,8]$, which we attribute to the insufficient length of the explants transferred to the substrate. Probably, an improvement in elongation could be achieved by keeping the explants in the elongation medium for longer to prolong the effect of $\mathrm{GA}_{3}$, or by previously excising the shoots from the explants, instead of introducing the entire explant to the medium, to avoid the depletion of hormones by competition between the shoots and with the present calli [38]. The data presented on elongation and rooting are preliminary since the main objective of this work was the study of the organogenic response of pepper to different stimuli. We suggest that an improvement of the regeneration protocol is necessary for a substantial improvement of the acclimatization phase.

\section{Conclusions}

We have demonstrated the significant effect of the culture medium, the type of explant and genotype on the organogenesis of pepper, a crop that is very recalcitrant to in vitro regeneration. In general, the most effective medium for the direct organogenesis of Capsicum was Pep1 + Pep1.2 (a combination of IAA, BAP, $\mathrm{CuSO}_{4}$ and $\mathrm{AgNO}_{3}$ ), probably due to the synergistic effect of copper and silver. We aim to test this medium in future experiments in order to validate its efficiency in other accessions or cultivars within each of the species, to establish a widely applicable protocol for Capsicum pepper regeneration. Out of the three evaluated species, C. baccatum displayed the highest regeneration response, followed by C. annuum. C. chinense presented a low regeneration capacity with the media used, so it is necessary to continue researching this species. Cotyledon was the most organogenic explant for the three species, so it is proposed as the best explant option for the regeneration of Capsicum. Although an improvement is required for the elongation, rooting and acclimatization phases, this study provides relevant information for the improvement of pepper regeneration protocols, which is of great interest for the application of plant breeding and gene editing technologies requiring in vitro regeneration in Capsicum.

Author Contributions: Conceptualization, M.M.-L., J.P., S.V. and E.G.-F.; methodology, M.M.-L., A.G.-P., E.G.-P. and E.G.-F.; software, S.V.; validation, J.P., S.V. and E.G.-F.; formal analysis, M.M.-L. and E.G.-F.; investigation, M.M.-L. and E.G.-F.; resources, J.P. and S.V.; data curation, M.M.-L. and E.G.-F.; writing—original draft, M.M.-L. and E.G.-F.; writing—review and editing, J.P. and S.V.; visualization, E.G.-F.; supervision, E.G.-F.; project administration, J.P. and E.G.-F.; funding acquisition, J.P. All authors have read and agreed to the published version of the manuscript.

Funding: This research was funded by Universitat Politècnica de València, research line 20200268.

Institutional Review Board Statement: Not applicable.

Informed Consent Statement: Not applicable.

Data Availability Statement: The datasets used and/or analyzed in the current study are available from the corresponding author on reasonable request.

Conflicts of Interest: The authors declare there is no conflict of interest.

\section{References}

1. FAOSTAT (Food and Agriculture of Organization of the United Nations Statistics Database). Available online: http://www.fao. org/faostat/es/\#data/QC (accessed on 16 June 2021).

2. Tripodi, P.; Kumar, S. The Capsicum Crop: An Introduction. In The Capsicum Genome; Ramchiary, N., Kole, C., Eds.; Compendium of Plant Genomes Springer Nature: Cham, Switzerland, 2019; pp. 1-8. [CrossRef]

3. Monteiro do Rêgo, M.; Ramalho do Rêgo, E.; Barroso, P.A. Tissue Culture of Capsicum spp. In Production and Breeding of Chilli Peppers (Capsicum spp.); Springer International Publishing: Cham, Switzerland, 2016; pp. 97-127. [CrossRef]

4. Park, S.; Kim, H.-B.; Jeon, H.-J.; Kim, H. Agrobacterium-mediated Capsicum annuum gene editing in two cultivars, hot pepper CM334 and bell pepper Dempsey. Int. J. Mol. Sci. 2021, 22, 3921. [CrossRef]

5. Gunay, A.; Rao, P. In Vitro plant regeneration from hypocotyl and cotyledon explants of red pepper (Capsicum). Plant Sci. Lett. 1978, 11, 365-372. [CrossRef] 
6. Kothari, S.; Joshi, A.; Kachhwaha, S.; Ochoa-Alejo, N. Chilli peppers-A review on tissue culture and transgenesis. Biotechnol. Adv. 2010, 28, 35-48. [CrossRef] [PubMed]

7. Sanatombi, K.; Sharma, G. In Vitro plant regeneration in six cultivars of Capsicum spp. using different explants. Biol. Plant. 2008, 52, 141-145. [CrossRef]

8. Kumar, A.; Rupavathi, O.; Tata, S. Adventitious shoot bud induction in chili pepper (Capsicum annuum L. CV. x-235). Int. J. Sci. Nat. 2012, 3, 192-196.

9. Orlińska, M.; Nowaczyk, P. In Vitro plant regeneration of 4 Capsicum spp. Genotypes using different explant types. Turk. J. Biol. 2015, 39, 60-68. [CrossRef]

10. Gammoudi, N.; Pedro, T.; Ferchichi, A.; Gisbert, C. Improvement of regeneration in pepper: A recalcitrant species. Plant. Vitr. Cell. Dev. Biol. Plant 2018, 54, 145-153. [CrossRef]

11. Bora, G.; Gogoi, H.; Handique, P. Influence of silver nitrate and glutamine on in vitro organogenesis of lota bhot (Capsicum chinense Jacq.), an indigenous pungent pepper variety of Assam. J. Appl. Biol. Biotechnol. 2019, 7, 21-28. [CrossRef]

12. Ashwani, S.; Ravishankar, G.A.; Giridhar, P. Silver nitrate and 2-(N-morpholine) ethane sulphonic acid in culture medium promotes rapid shoot regeneration from the proximal zone of the leaf of Capsicum frutescens Mill. Plant. Cell Tissue Organ. Cult. 2017, 129, 175-180. [CrossRef]

13. Joshi, A.; Kothari, S. High copper levels in the medium improves shoot bud differentiation and elongation from the cultured cotyledons of Capsicum annuum L. Plant. Cell Tissue Organ. Cult. 2007, 88, 127-133. [CrossRef]

14. Valadez-Bustos, M.; Aguado-Santacruz, G.; Carrillo-Castañeda, G.; Aguilar-Rincón, V.; Espitia-RangeL, E.; Montes-Hernández, S.; Robledo-Paz, A. In vitro propagation and agronomic performance of regenerated chili pepper (Capsicum spp.) plants from commercially important genotypes. Vitr. Cell. Dev. Biol. Plant 2009, 45, 650-658. [CrossRef]

15. Dabauza, M.; Peña, L. High efficiency organogenesis in sweet pepper (Capsicum annuum L.) Tissues from different seedling explants. Plant. Growth Regul. 2001, 33, 221-229. [CrossRef]

16. Hailu, T.; Abera, B.; Shekata, J. In Vitro Direct Organogenesis Protocol for Mass Propagation of an Elite Ethiopian Hot Pepper (Capsicum annuum L.) Cultivar: Mareko Fana. Am. J. Plant Sci. 2015, 6, 1435-1443. [CrossRef]

17. Bora, G.; Gogoi, H.K.; Jyoti Handique, P. Micropropagation of Capsicum chinense Jacq. cv. Lota Bhot via indirect organogenesis molecular mechanisms of smut formation in economically important crops. Int. J. Agric. Sci. 2014, 6, 384-387. [CrossRef]

18. Golegaonkar, P.; Kantharajah, A. High-frequency adventitious shoot bud induction and shoot elongation of chile pepper (Capsicum annuum L.). Vitr. Cell. Dev. Biol. Plant 2006, 42, 341-344. [CrossRef]

19. Manzur, J.P.; Fita, A.; Prohens, J.; Rodríguez-Burruezo, A. Successful hybridization and introgression breeding in a diverse set of common peppers (Capsicum annuum) using different cultivated ají (C. baccatum) accessions as donor parents. PLoS ONE 2015, 10, e0144142. [CrossRef]

20. García-Fortea, E.; Lluch-Ruiz, A.; Pineda-Chaza, B.; García-Pérez, A.; Bracho-Gil, J.; Plazas, M.; Gramazio, P.; Vilanova, S.; Moreno, V.; Prohens, J. A highly efficient organogenesis protocol based on zeatin riboside for in vitro regeneration of eggplant. BMC Plant. Biol. 2020, 20, 6. [CrossRef] [PubMed]

21. Chee, M.; Lycett, G.; Chin, C. Development of a direct transformation method by GFP screening and in vitro whole plant regeneration of Capsicum frutescens L. Electron. J. Biotechnol. 2018, 34, 51-58. [CrossRef]

22. Murashige, T.; Skoog, F. A Revised Medium for Rapid Growth and Bio Assays with Tobacco Tissue Cultures. Physiol. Plant. 1962, 15, 473-497. [CrossRef]

23. Ihaka, R.; Gentleman, R. A Language for Data Analysis and Graphics. J. Comput. Graph. Stat. 2012, 5, 299-314. [CrossRef]

24. Zemene, A.; Worku, A. Protocol optimization for micro-propagation of Green pepper (Capsicum annuum L.) cultivated in Ethiopia. J. Med. Plants Stud. 2018, 6, 229-234.

25. Abdalmajid, N.; Mohd, R.; Mihdzar, A.; Halimi, M. In vitro performances of hypocotyl and cotyledon explants of tomato cultivars under sodium chloride stress. Afr. J. Biotechnol. 2011, 10, 8757-8764. [CrossRef]

26. Souza, F.; Garcia-Sogo, B.; Souza, A.; San-Juán, A.; Moreno, V. Morphogenetic response of cotyledon and leaf explants of melon (Cucumis melo L.) cv. Amarillo Oro. Braz. Arch. Biol. Technol. 2006, 49, 21-27. [CrossRef]

27. Christopher, T.; Rajam, M. Effect of genotype, explant and medium on in vitro regeneration of red pepper. Plant. Cell Tissue Organ. Cult. 1996, 46, 245-250. [CrossRef]

28. Trujillo-Moya, C.; Gisbert, C. The influence of ethylene and ethylene modulators on shoot organogenesis in tomato. Plant. Cell Tissue Organ. Cult. 2012, 111, 41-48. [CrossRef]

29. Hussain, S.; Ali, S.; Ahmad Jan, S.; Ud-Din, J.; Ghulam, M.A. Assessment of silver nitrate on callus induction and in vitro shoot regeneration in tomato (Solanum lycopersicum mill.). Pak. J. Bot. 2014, 46, 2163-2174.

30. Alva Ticona, S.; Oropeza, M. Effect of culture medium consistence and silver nitrate on micropropagation of two potato (Solanum tuberosum) cultivars. Rev. Colomb. Biotecnol. 2013, 15, 55-62. [CrossRef]

31. Kaur, A.; Reddy, M.; Kumar, A. Efficient, one step and cultivar independent shoot organogenesis of potato. Physiol. Mol. Biol. Plants 2017, 23, 461-469. [CrossRef] [PubMed]

32. Papani, S.; Naidu, C.V. Antagonistic effect of silver nitrate and cobalt chloride against ethylene action to enhance in vitro regeneration potency of Solanum viarum Dunual. Int. J. Innov. Res. Adv. Stud. 2015, 2, 40-44.

33. Geetha, G.; Harathi, K.; Naidu, C. Role of silver nitrate on in vitro flowering and shoot regeneration of Solanum nigrum (L.)-An Important Multipurpose Medicinal Plant. Am. J. Plant. Sci. 2016, 7, 1021-1032. [CrossRef] 
34. Núñez-Pastrana, R.; Arcos-Ortega, G.F.; Souza-Perera, R.A.; Sánchez-Borges, C.A.; Nakazawa-Ueji, Y.E.; García-Villalobos, F.J.; Guzmán-Antonio, A.A.; Zúñiga-Aguilar, J.J. Ethylene, but not salicylic acid or methyl jasmonate, induces a resistance response against Phytophthora capsici in Habanero pepper. Eur. J. Plant. Pathol. 2011, 131, 669. [CrossRef]

35. Grozeva, S. Effect of copper levels in the culture medium on shoot regeneration in pepper. Banat. J. Biotechnol. 2015, 6, 86. [CrossRef]

36. Ciardi, J.; Klee, H. Regulation of ethylene-mediated responses at the level of the receptor. Ann. Bot. 2001, 88, 813-822. [CrossRef]

37. İzgü, T.; İlbi, H.; Mendi, Y.Y. Optimization of plant regeneration in different pepper (Capsicum annuum L.) lines. Turk. J. Agric. Food Sci. Tech. 2020, 8, 471. [CrossRef]

38. Robledo, P.; Carrillo, G. Regeneración in vitro de plantas de chile (Capsicum annuum L.) mediante cultivo de cotiledones e hipocótilos. Rev. Fitotec. Mex. 2004, 27, 121-126. 